Volume 3, Issue 9, September-2016, pp. 461-471 ISSN (0): 2349-7084

International Journal of Computer Engineering In Research Trends IJCERT

Available online at: www.ijcert.org

\title{
Analytical and Parametric Optimization of Force Transmissibility by Taguchi Method for Double Stage Engine Mountings
}

\author{
G.C.Mekalke1, R.R.Kolhapure ${ }^{2}$ \\ DKTE'S Textile and Engineering Institute, Ichalkaranji
}

\begin{abstract}
It is essential to design a warship to avoid detection by submarines or enemy ships. One of the recent techniques used is to mount all vibrant machinery on a double stage vibration isolation system. For high structure-borne noise attenuation there is requirement of two-stage mounting system. The main goal of current research work is to reduce vibration levels from machinery to foundation, and thereby to reduce radiate noise levels from ship hull. The present work deals with the mathematical modeling and parametric optimization of force transmissibility (Ftr) for design of engine foundation system. The vertical vibrations of the system are assumed to be most predominant, and other types of vibrations are neglected. The research work is carried out for finding parameters of mounts and optimizing the same. The analysis is based on discrete system modeling. Taguchi method is used for finding optimal combination of process parameters based on $\mathrm{S} / \mathrm{N}$ ratio and analysis of variance (ANOVA) is statistical technique to investigate contribution of each process parameters on the performance characteristic. The result shows that spring stiffness is most affecting process parameter.
\end{abstract}

Keywords: Double stage vibration isolation, Two-degree freedom systems, Taguchi, ANOVA

\section{INTRODUCTION}

In case of a warship, engine foundations are usually designed as a double stage foundation in which engine is mounted on anti-vibration mounts which are further mounted on a raft foundation. This raft is again supported on the hull girder through another set up of springs and dampers which act as the second layer mounts. The hull girder may be treated as the fixed support. Thus the engine-mount-foundation system can be modelled as a two-degree freedom system with certain assumptions.

Double mounting is an isolation practice in which two mounts are separated by auxiliary mass at each location. This serves two objectives as follows to isolate base from engine vibration (force transmissibility) 


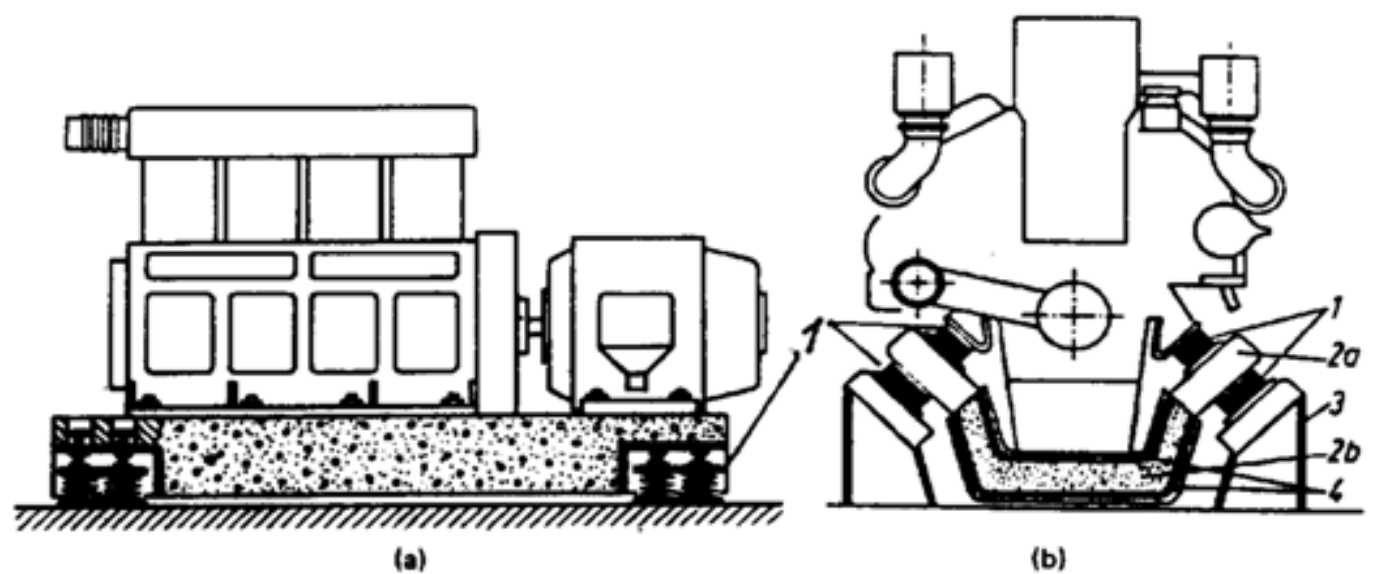

Figure 1. Resilient mounting system: (a) single stage system (b) double stage system

1] Resilient support mountings; 2] intermediate foundation (a) steel, (b) frame structure; 3] seating; 4] damping layer.

These are used in vehicular or luxury watercraft applications [1]. This change from single stage mounting to double stage mounting, results in reducing the transmissibility of forces to the foundation. Robust mounting systems of engines provides a powerful means of isolating structure borne sound on its path, from the engine to the foundation. Improvement of the mounting system may be achieved by converting single stage to a double stage mounting system. [1] Marine diesel engines are supported by mounts. These mounts are designed to provide both structural rigidity and vibration isolation. The need of Structural rigidity is for maintaining alignment of connecting shafts and piping whereas vibration isolation is needed to minimize the vibrations generated from the engine from being transmitted to the rest of vessel and beyond. The mounts are generally made of elastomers. The complex constitutive characteristics of the elastomers and also the complex nature of three dimensional vibration motion of the engine make optimal design of these mounts complicated, from vibration point of view [2].
An engine foundation required to have dynamic stability and hence a reasonably accurate theoretical treatment is required. The objective of current research work is designing an optimal marine engine foundation system which would resemble a two-degree freedom system.

\section{REQUIREMENTS OF THE DESIGN}

The challenge for the design engineer is selecting suitable vibration isolators and properly installing them in order to minimize the structure-borne noise and vibration level in the cabins or noise breakout into the water which is especially critical for warships. A marine engine subjected to the strong dynamic forces produced by docking impact, wave slap, and cornering loads. Therefore, the mounting system of marine engine should be able to withstand these forces. To maintain the balance of engine under the strong impact loading, the static deflection of isolator has to be kept to a minimum. If the static deflection of isolator is more, this will increase the vibration transmitted into the hull structure and challenge the design engineer to create even more effective mounting system. Optimization techniques are 
G.C.Mekalke, R.R.Kolhapure," Analytical and Parametric Optimization of Force Transmissibility by Taguchi Method for Double Stage Engine Mountings", International Journal of Computer Engineering In Research Trends, Volume 3, Issue 9, September-2016, pp. 461-471

one of the methods to develop more effective mounting systems. The objective is minimizing the transmitted force by following method:

To directly optimize the force transmission by adjusting the design parameters.

In a warship study of total force transmitted to the structure is critical. The vertical force is a major factor in producing the structure-borne noise or vibration transmitted to the floor. The force normal to the base can excite the bending wave which contributes most of energy of structureborne noise. Hence it is necessary to minimize the transmitted force normal to the base [3].

\section{MATHEMATICAL MODELING}

Modeling of the system can be done with various assumptions. Consider the following case considering only an engine or a machine mounted on a concrete foundation.

If the engine or machine bed is mounted on isolator which are supported by inertia blocks which are further supported by another set up of isolator which rest on a rigid floor, for e.g. the hull girder of a ship (as shown in Figure1. (b)), then the system can be modeled as a two-degree freedom of system.

Further assumptions made are as follows, the exciting force should pass through the C.G. of the machine foundation system. The vertical vibrations are predominant and the transverse or rocking vibrations should be negligible which can be easily taken by the mounts.

\section{FORCED VIBRATIONS}

The further analysis is done for forced vibrations of a two-degree freedom model which represents an engine or a machine foundation system. This type of system is assumed to be subjected to a harmonic type of excitation force.
Hence the analysis has been done for forced vibrations arising due to an excitation force of $\mathrm{F} 0$ $\operatorname{Sin}(\omega t)$ i.e. the imaginary part of F0 ei $\omega t$. This leads to a steady state vibration. This analysis is more important as we are interested in getting the values of the amplitudes of the machine or engine bed $\mathrm{Xb}$ and foundation block $\mathrm{Xc}_{\mathrm{C}}$ at various frequencies. These have to be in an allowable range as per the design requirements.

The free body diagram of the two masses is as shown in Figure 2. The equations of motion for the two masses are as follows:

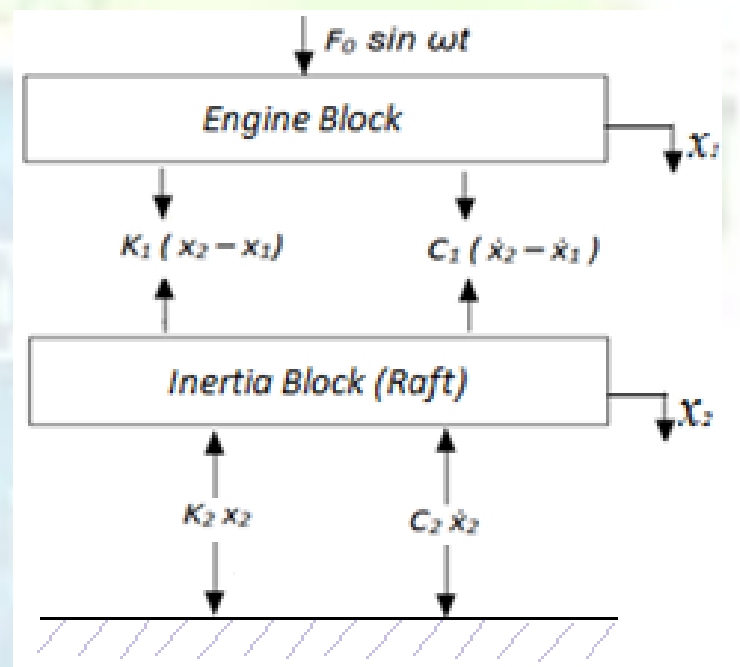

Figure 2. Free Body Diagram

$\mathrm{M}_{\mathrm{b}} \ddot{\mathrm{X}}_{\mathrm{b}} \quad \mathrm{C}_{1}\left(\dot{\mathrm{X}}_{\mathrm{c}}-\dot{\mathrm{X}}_{\mathrm{b}}\right)-\mathrm{K}_{1}\left(\mathrm{x}_{\mathrm{c}}-\mathrm{x}_{\mathrm{b}}\right)=\quad \mathrm{Im}$ $\left\{\mathrm{F}_{0} \mathrm{e}^{\mathrm{i} \omega \mathrm{t}}\right\} \ldots \ldots \ldots \ldots$....... (1)

$\mathrm{M}_{\mathrm{c}} \ddot{\mathrm{x}}_{\mathrm{c}}+\mathrm{C}_{1}\left(\dot{\mathrm{x}}_{\mathrm{c}}-\dot{\mathrm{X}}_{\mathrm{b}}\right)+\mathrm{K}_{1}\left(\mathrm{x}_{\mathrm{c}}-\right.$

$\left.\mathrm{x}_{\mathrm{b}}\right)+\mathrm{C}_{2} \dot{\mathrm{x}}_{\mathrm{c}}+\mathrm{K}_{2} \mathrm{x}_{\mathrm{c}}=0$.

Let us assume the solutions as $x_{b}=X_{b} e^{i \omega t}$ and $\mathrm{x}_{\mathrm{c}}=\mathrm{X}_{\mathrm{c}} \mathrm{e}^{\mathrm{i} \omega \mathrm{t}}$, substituting in the above equations We get:

$\left\{\left(-\mathrm{M}_{\mathrm{b}} \omega^{2}+\mathrm{K}_{1}\right)+\mathrm{i}\left(\mathrm{C}_{1} \omega\right)\right\} \mathrm{X}_{\mathrm{b}^{-}}\left\{\mathrm{K}_{1}+\mathrm{i}\left(\mathrm{C}_{1} \omega\right)\right\} \mathrm{X}_{\mathrm{c}}=\mathrm{F}_{0}-$ $\left\{\mathrm{K}_{1}+\mathrm{i}\left(\mathrm{C}_{1} \omega\right)\right\} \mathrm{X}_{\mathrm{b}}+\left\{\left(\mathrm{M}_{\mathrm{c}} \omega^{2}+\left[\mathrm{K}_{1}+\mathrm{K}_{2}\right]\right)+\mathrm{i}\left(\left[\mathrm{C}_{1}+\mathrm{C}_{2}\right]\right.\right.$ $\omega)\} X_{c}=0$.

Solving the above two equations we get complex values of $\mathrm{Xb}$ and $\mathrm{Xc}$. But by mathematical treatment we can get the values of magnitudes of $\mathrm{Xb}$ and $\mathrm{Xc}$. Solving the above equations, we get 
G.C.Mekalke, R.R.Kolhapure," Analytical and Parametric Optimization of Force Transmissibility by Taguchi Method for Double Stage Engine Mountings", International Journal of Computer Engineering In Research Trends, Volume 3, Issue 9, September-2016, pp. 461-471

the amplitudes of engine bed and concrete inertia block as

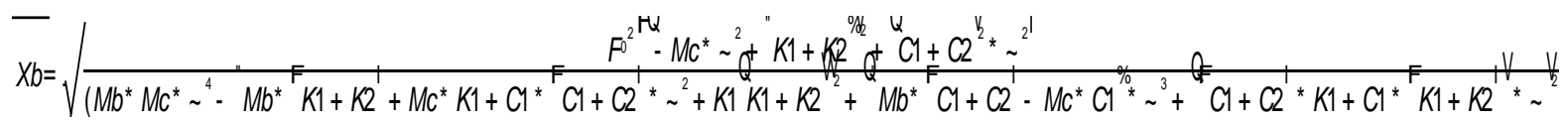

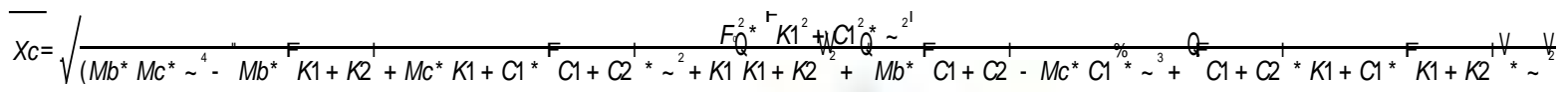

The general solution consists of the complimentary function and particular integral and is of nature $\mathrm{X}=\mathrm{X}$ (complimentary function) $+\mathrm{X}$ (particular integral)......

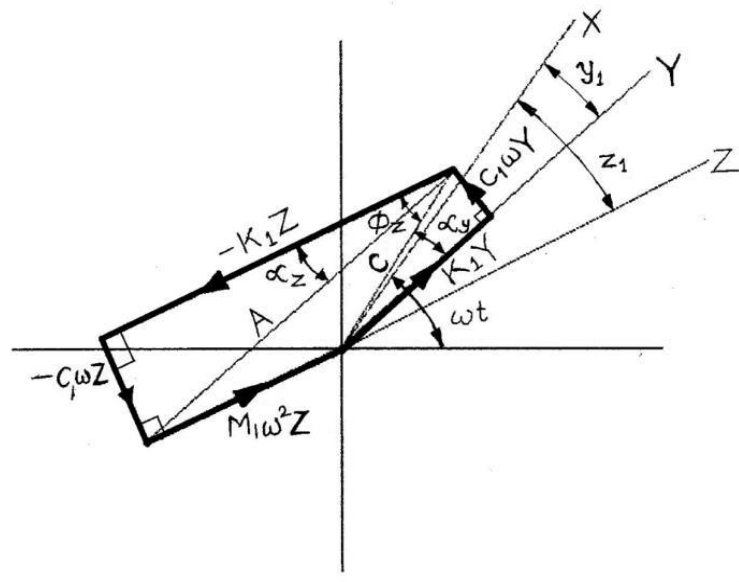

Figure 3. Equilibrium of forces at mass $\mathrm{M}_{1}$ Out of this $\mathrm{X}$ complimentary function (which has been dealt with in the previous section) dies out in a short time and $X$ particular integral represents the steady state vibration. Also as the forcing function has been the imaginary part of F0 $\mathrm{e}^{\mathrm{i} \omega \mathrm{t}}$, the final steady state motion of the two masses would be given by

$\mathrm{x}_{\mathrm{b}}=\mathrm{X}_{\mathrm{b}} \quad \sin (\omega \mathrm{t}-\psi 1)$ and $\mathrm{x}_{\mathrm{c}}=\mathrm{X}_{\mathrm{c}} \quad \sin (\omega \mathrm{t}-$ $\psi 2)$.

The solution for the equations for displacement will be sinusoidal motion with the amplitudes $\mathrm{Xb}$ for the machin bed and $X_{c}$ for the foundation block. $\Psi 1$ and $\psi 2$ are constants to be found out from initial conditions.

(C) 2016, IJCERT All Rights Reserved

DOI: 10.22362/ijcert/2016/v3/i9/48864

\section{TAGUCHI DESIGN}

Taguchi method includes reducing the variation in a process through robust design of experiments. The Taguchi method was developed by Dr. Genichi Taguchi of Japan who maintained that variation.

Taguchi involves use of orthogonal arrays to organize the parameters affecting the process and the levels at which they should be varies. Instead of having to test all possible combinations, the Taguchi method tests pairs of combinations.

This allows for the collection of the necessary data to determine which factors most affect product quality with a minimum amount of experimentation [14]. Taguchi methods provide an efficient and systematic way for optimizing designs for performance, quality as well as cost. Taguchi 
G.C.Mekalke, R.R.Kolhapure," Analytical and Parametric Optimization of Force Transmissibility by Taguchi Method for Double Stage Engine Mountings", International Journal of Computer Engineering In Research Trends, Volume 3, Issue 9, September-2016, pp. 461-471

methods have been widely used for product design and process optimization [13]. Analysis of variance (ANOVA) is used to for finding out which process parameter is statistically significant and the contribution of each process parameter towards the output characteristic. With the main effect and ANOVA analyses, possible combination of optimum parameters can be predicted [11-12]. For current research work force transmissibility is a process parameter which is to be minimize. The quality characteristic for Ftr is taken as of smaller the better type. The $\mathrm{S} / \mathrm{N}$ ratio for the smaller the better type of response can be computed by using Eq.10 as, $\mathrm{n}=-10 \log _{10}$ [mean of sum of squares of measured data]

$$
n=-10 \log _{10}\left(\frac{1}{R} \sum_{j=1}^{R} y_{j}^{2}\right)
$$

Where $y j=$ is the response value

Selection of a particular OA is based on the number of levels of various factors. Here, four parameters each at five levels represent in Table 1, therefore Degree of Freedom (DOF) can be calculated as, Eq.11

$$
D O F=P \times(L-1)
$$

Eq.11

$$
\text { DOF }=4 \times(5-1)=16
$$

Table 1: Selecting critical parameters and levels

\begin{tabular}{|l|l|l|l|l|l|l|l|}
\hline Sr. No. & Parameters & Unit & Level 1 & Level 2 & Level 3 & Level 4 & Level \\
\hline 1 & C1 & Ns/m & 400 & 800 & 1200 & 1600 & 2000 \\
\hline 2 & C2 & Ns/m & 400 & 800 & 1200 & 1600 & 2000 \\
\hline 3 & K1 & N/m & $1 \mathrm{E}+05$ & $2 \mathrm{E}+05$ & $3 \mathrm{E}+05$ & $4 \mathrm{E}+05$ & $5 \mathrm{E}+05$ \\
\hline 4 & K2 & N/m & $1 \mathrm{E}+05$ & 2E+05 & $3 \mathrm{E}+05$ & $4 \mathrm{E}+05$ & $5 \mathrm{E}+05$ \\
\hline
\end{tabular}

$\mathrm{P}=$ number of factors, $\mathrm{L}=$ number of levels

\section{Effect of process parameters on Ftr}

In order to see the effect of parameters on Ftr, experiments are conducted using L25 OA with S/N ratios shown in Table 2.

Table 2: S/N ratio for Ftr

\begin{tabular}{|c|c|c|c|c|l|l|}
\hline $\begin{array}{l}\text { Expt. } \\
\text { No. }\end{array}$ & 1 & 2 & 3 & 4 & Ftr & \multicolumn{1}{c|}{$\begin{array}{c}\text { S/N } \\
\text { Ratio } \\
\text { (Smaller } \\
\text { is better) }\end{array}$} \\
\hline 1 & 400 & 400 & $1 \mathrm{E}+05$ & $1 \mathrm{E}+05$ & 0.129 & 17.767 \\
\hline 2 & 400 & 800 & $2 \mathrm{E}+05$ & $2 \mathrm{E}+05$ & 0.293 & 10.672 \\
\hline 3 & 400 & 1200 & $3 \mathrm{E}+05$ & $3 \mathrm{E}+05$ & 0.511 & 5.825 \\
\hline 4 & 400 & 1600 & $4 \mathrm{E}+05$ & $4 \mathrm{E}+05$ & 0.819 & 1.732 \\
\hline 5 & 400 & 2000 & $5 \mathrm{E}+05$ & $5 \mathrm{E}+05$ & 1.284 & -2.173 \\
\hline
\end{tabular}


G.C.Mekalke, R.R.Kolhapure," Analytical and Parametric Optimization of Force Transmissibility by Taguchi Method for Double Stage Engine Mountings", International Journal of Computer Engineering In Research Trends, Volume 3, Issue 9, September-2016, pp. 461-471

\begin{tabular}{|c|c|c|c|c|c|c|}
\hline 6 & 800 & 400 & $2 \mathrm{E}+05$ & $3 \mathrm{E}+05$ & 0.372 & 8.579 \\
\hline 7 & 800 & 800 & $3 E+05$ & $4 \mathrm{E}+05$ & 0.630 & 4.012 \\
\hline 8 & 800 & 1200 & $4 \mathrm{E}+05$ & $5 \mathrm{E}+05$ & 1.001 & -0.009 \\
\hline 9 & 800 & 1600 & $5 \mathrm{E}+05$ & $1 \mathrm{E}+05$ & 0.232 & 12.699 \\
\hline 10 & 800 & 2000 & $1 \mathrm{E}+05$ & $2 E+05$ & 0.179 & 14.934 \\
\hline 11 & 1200 & 400 & $3 E+05$ & $5 E+05$ & 0.732 & 2.707 \\
\hline 12 & 1200 & 800 & $4 \mathrm{E}+05$ & $1 \mathrm{E}+05$ & 0.220 & 13.151 \\
\hline 13 & 1200 & 1200 & $5 E+05$ & $2 \mathrm{E}+05$ & 0.473 & 6.495 \\
\hline 14 & 1200 & 1600 & $1 \mathrm{E}+05$ & $3 E+05$ & 0.206 & 13.736 \\
\hline 15 & 1200 & 2000 & $2 E+05$ & $4 \mathrm{E}+05$ & 0.431 & 7.304 \\
\hline 16 & 1600 & 400 & $4 \mathrm{E}+05$ & $2 \mathrm{E}+05$ & 0.429 & 7.349 \\
\hline 17 & 1600 & 800 & $5 E+05$ & $3 \mathrm{E}+05$ & 0.729 & 2.746 \\
\hline 18 & 1600 & 1200 & $1 \mathrm{E}+05$ & $4 \mathrm{E}+05$ & 0.223 & 13.052 \\
\hline 19 & 1600 & 1600 & $2 \mathrm{E}+05$ & $5 \mathrm{E}+05$ & 0.477 & 6.436 \\
\hline 20 & 1600 & 2000 & $3 E+05$ & $1 E+05$ & 0.205 & 13.745 \\
\hline 21 & 2000 & 400 & $5 E+05$ & $4 \mathrm{E}+05$ & 0.999 & 0.009 \\
\hline 22 & 2000 & 800 & $1 \mathrm{E}+05$ & $5 E+05$ & 0.234 & 12.601 \\
\hline 23 & 2000 & 1200 & $2 \mathrm{E}+05$ & $1 \mathrm{E}+05$ & 0.179 & 14.959 \\
\hline 24 & 2000 & 1600 & $3 E+05$ & $2 \mathrm{E}+05$ & 0.372 & 8.595 \\
\hline 25 & 2000 & 2000 & $4 \mathrm{E}+05$ & $3 E+05$ & 0.629 & 4.029 \\
\hline
\end{tabular}




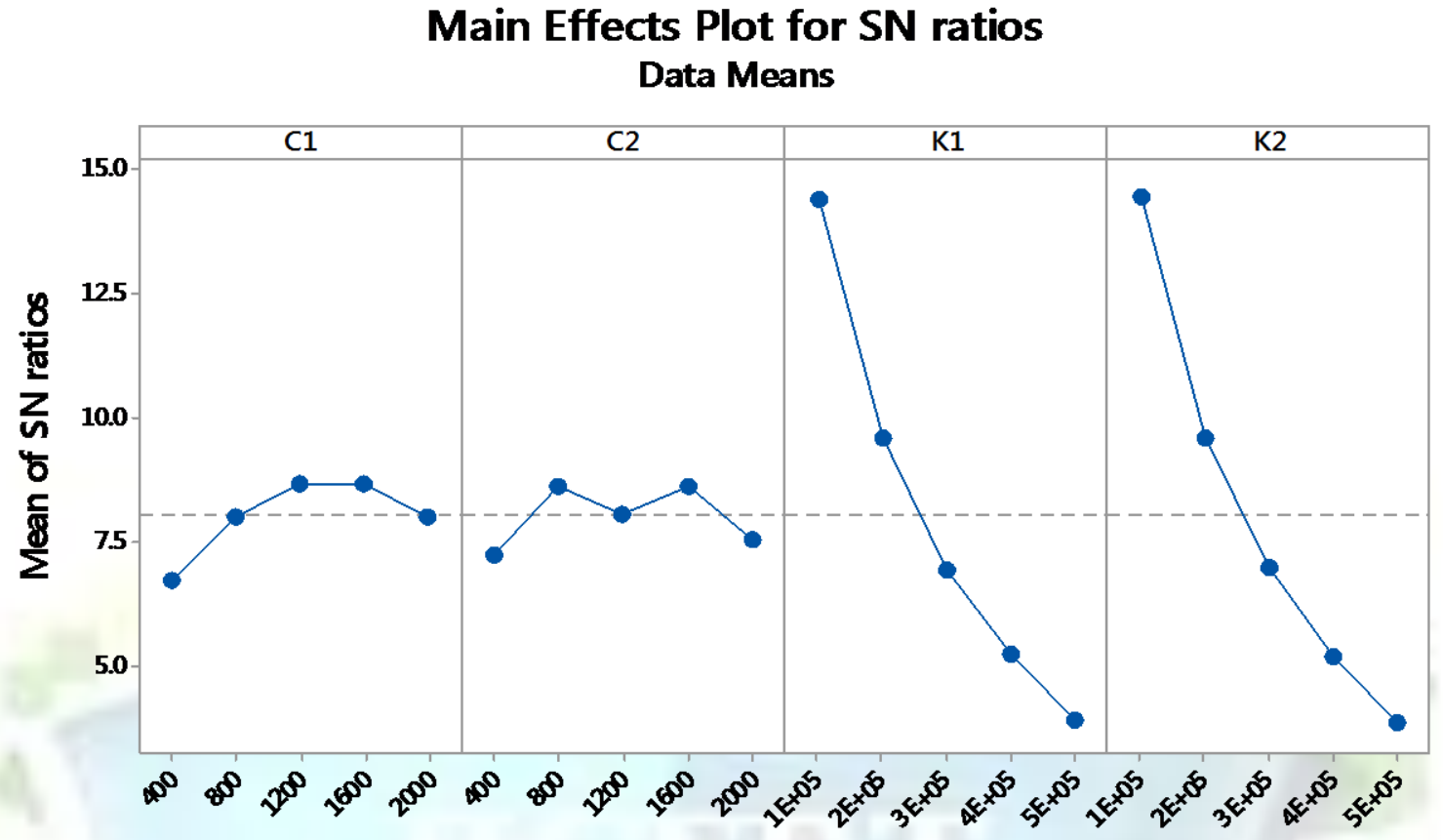

Signal-to-noise: Smaller is better

Figure 4. Effect of process parameters on Ftr

In order to see the effect of process parameters on the Ftr, experiments were conducted using L25 OA (Table 2). The experimental data and $\mathrm{S} / \mathrm{N}$ ratios are given in Table 2. Figure 4 shows that the Ftr decrease with the increase in stiffness of spring (K1 \& K2) whereas Ftr initially increase with C1 then constant and finally decrease and for $\mathrm{C} 2$ it is finally drastically decreases.

Table 3: ANOVA for Ftr

\begin{tabular}{|c|c|c|c|c|c|c|c|}
\hline Parameters & DOF & Seq SS & Adj SS & Adj MS & F & P & \% C \\
\hline C1 & 4 & 0.1267 & 0.1267 & 0.03168 & 1.54 & 0.279 & 5.63 \\
\hline C2 & 4 & 0.0701 & 0.07011 & 0.01753 & 0.85 & 0.531 & 3.11 \\
\hline K1 & 4 & 0.9374 & 0.9374 & 0.2343 & 11.40 & 0.002 & 41.69 \\
\hline K2 & 4 & 0.9492 & 0.9492 & 0.2373 & 11.54 & 0.002 & 42.22 \\
\hline Error & 8 & 0.1644 & 0.1644 & 0.0205 & & & 7.31 \\
\hline Total & 24 & 2.2481 & & & & & \\
\hline
\end{tabular}

Table 4: Response table

\begin{tabular}{|c|c|c|c|c|}
\hline Levels & C1 & C2 & K1 & K2 \\
\hline 1 & 0.6074 & 0.5324 & 0.1942 & 0.1930 \\
\hline 2 & 0.4829 & 0.4212 & 0.3504 & 0.3492 \\
\hline 3 & 0.4125 & 0.4774 & 0.4902 & 0.4895 \\
\hline
\end{tabular}


G.C.Mekalke, R.R.Kolhapure," Analytical and Parametric Optimization of Force Transmissibility by Taguchi Method for Double Stage Engine Mountings", International Journal of Computer Engineering In Research Trends, Volume 3, Issue 9, September-2016, pp. 461-471

\begin{tabular}{|c|c|c|c|c|}
\hline 4 & 0.4125 & 0.4210 & 0.6196 & 0.6204 \\
\hline 5 & 0.4825 & 0.5458 & 0.7435 & 0.7457 \\
\hline Delta & 0.1949 & 0.1248 & 0.5493 & 0.5527 \\
\hline Rank & 3 & 4 & 2 & 1 \\
\hline
\end{tabular}

To study the significance of process variables towards Ftr, analysis of variance (ANOVA) was performed as shown in Table 3. It is observed that parameter $\mathrm{K} 2$ has greatest effect on Ftr and is followed by K1, C1 and C2. Table 4 shows average of each response characteristic for each parameter level. This table give information about the ranks based on delta statistics, which compare the relative magnitude of effects. The delta statistic is the highest value, minus the lowest average for each parameter. The Minitab17 software tool is used to analyze these parameters. The ranks are assigned based on delta values such as the rank 1 to the highest delta value, rank 2 to the second highest and so on. The ranks indicate the relative importance of each parameter to the response. The ranks and the delta values are shown in Table 4, these also indicates the $\mathrm{K} 1$ has the greatest effect on Ftr compared to other parameters.

\section{COMPUTATIONS}

In this paper we are actually calculating the values of all the Ftr by taking the no. of values of spring stiffness, damping coefficients.

\section{FTR}

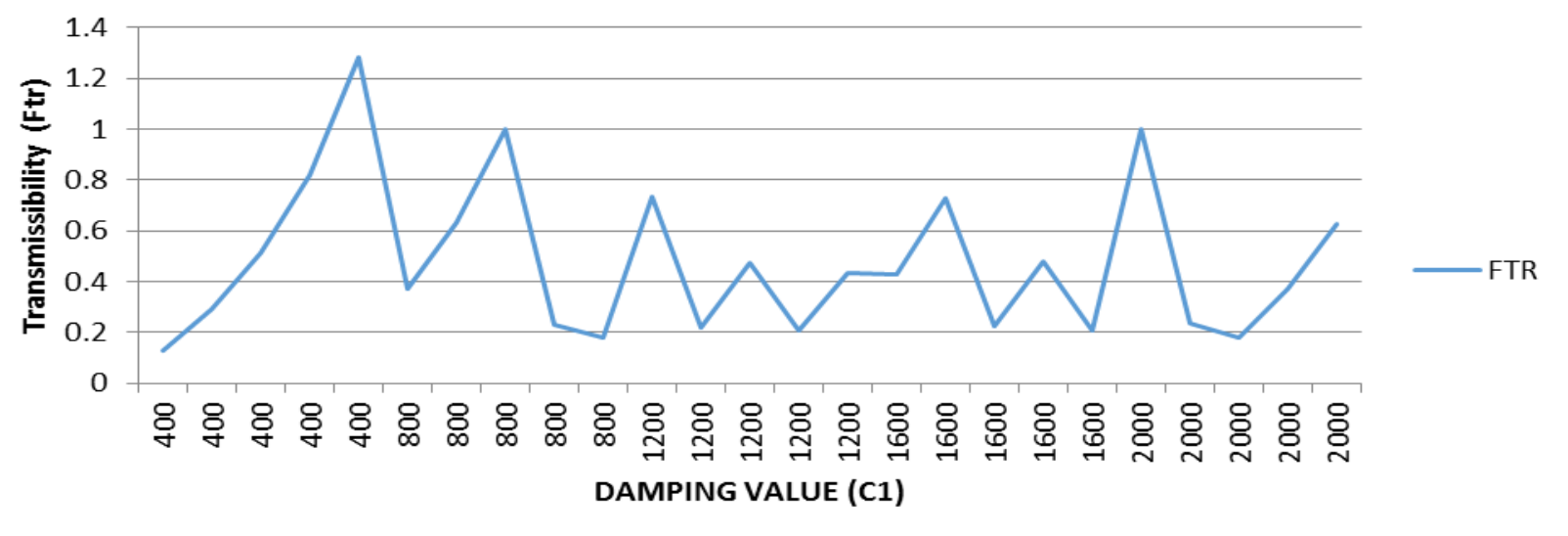

Figure 4. Graph of Ftr Vs. Damping Value (C1) 


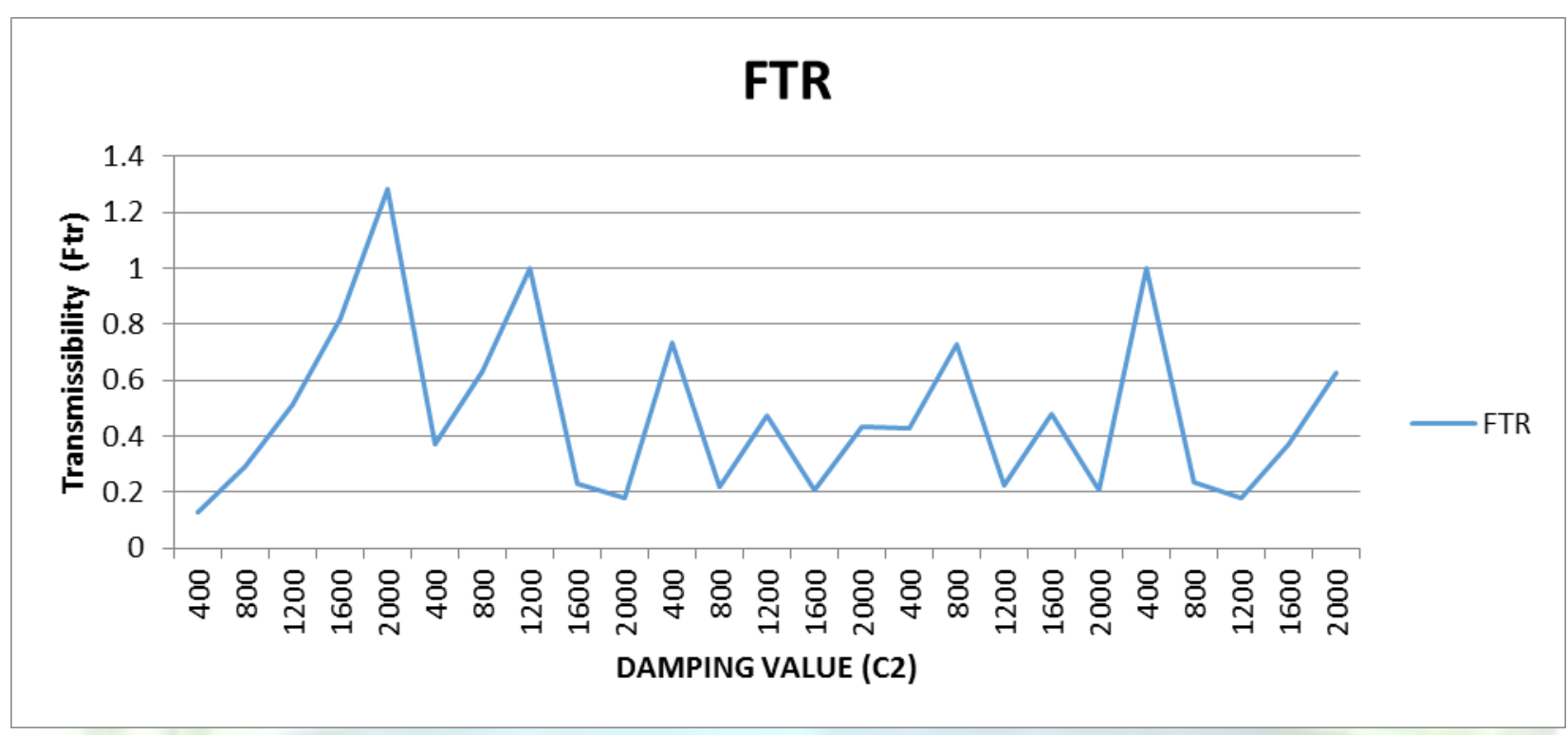

Figure 5. Graph of Ftr Vs. Damping Value (C2)

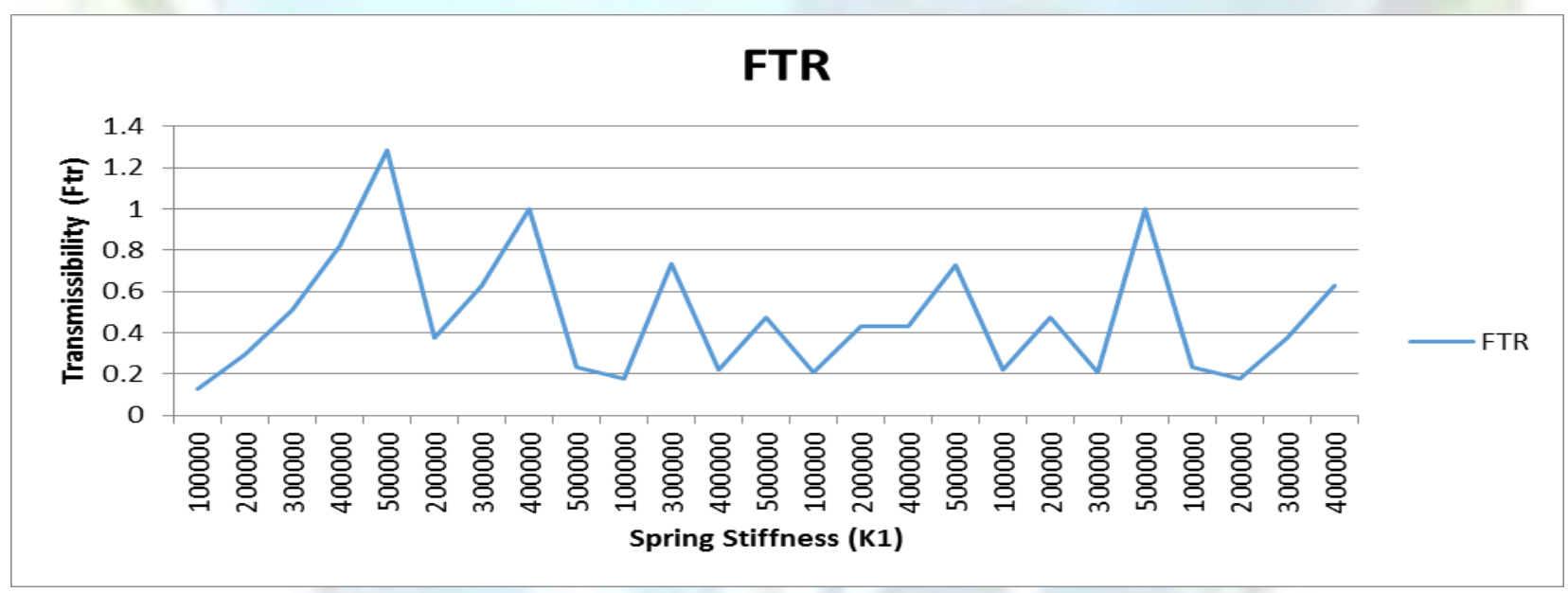

Figure 6. Graph of Ftr Vs. Spring Stiffness (K1) 
G.C.Mekalke, R.R.Kolhapure," Analytical and Parametric Optimization of Force Transmissibility by Taguchi Method for Double Stage Engine Mountings", International Journal of Computer Engineering In Research Trends, Volume 3, Issue 9, September-2016, pp. 461-471

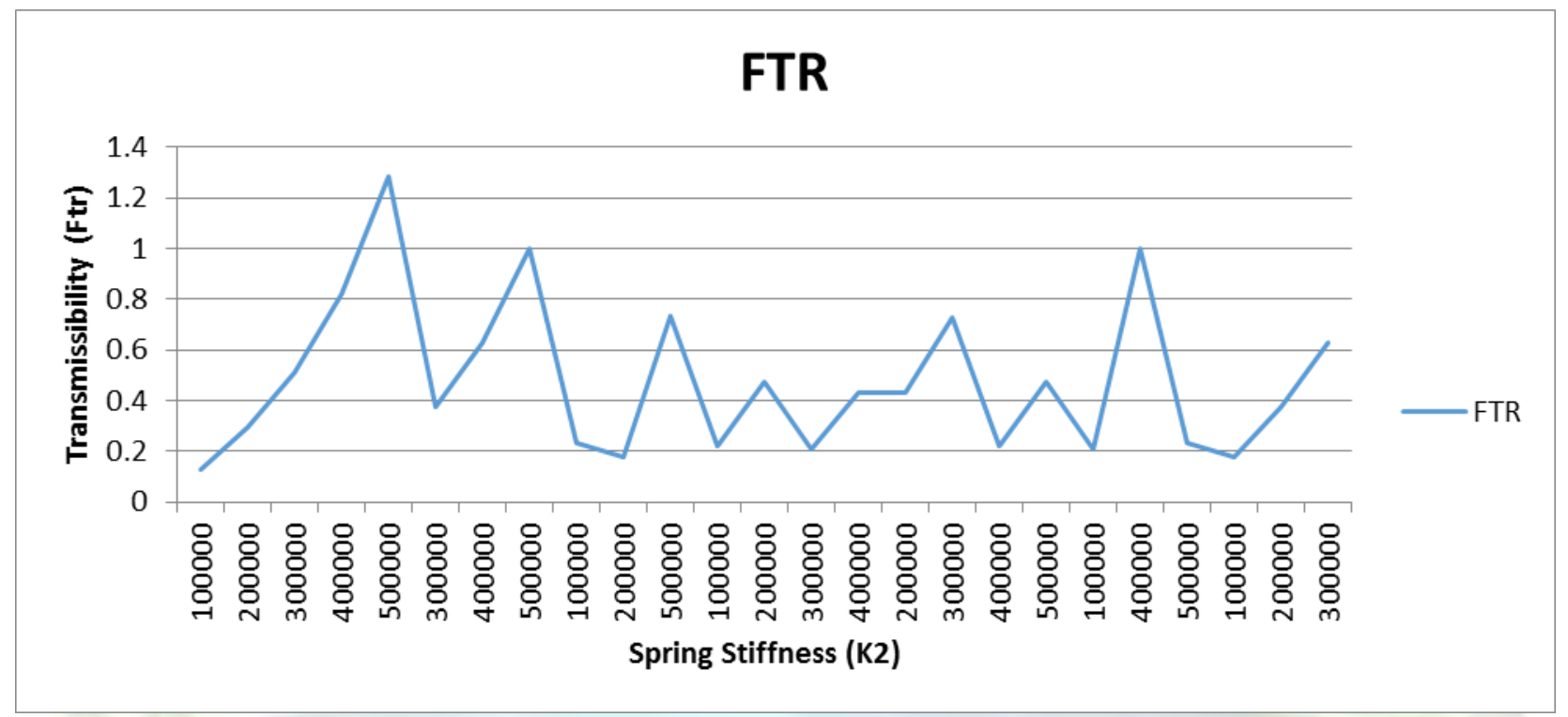

Figure 6. Graph of Ftr Vs. Spring Stiffness (K2)

From the above graphs it is clear that the value of Ftr is smaller (i.e.Ftr=01293) for combination of $\mathrm{C} 1=400 \mathrm{~N} / \mathrm{Mm}, \mathrm{C} 2=400 \mathrm{~N} / \mathrm{m}, \mathrm{K} 1=1 \mathrm{E} 6 \mathrm{~N} / \mathrm{mS}, \mathrm{K} 2=1 \mathrm{E} 6 \mathrm{~N} / \mathrm{mS}$.

\section{CONCLUSIONS}

The aim of research work is to find the optimum value of Ftr by using Taguchi method and compare with mathematical modelling. The conclusion based on above methods are summarized below,

1. Based on Taguchi with L25 orthogonal array and mathematical modeling it is found that expt. no 1 i.e. $\mathrm{C} 1=200 \mathrm{Ns} / \mathrm{m}$, $\mathrm{C} 2=200 \mathrm{Ns} / \mathrm{m}, \mathrm{K} 1=1 \mathrm{E} 6 \mathrm{~N} / \mathrm{m}, \mathrm{K} 2=1 \mathrm{E} 6 \mathrm{~N} / \mathrm{m}$ gives us minimum value of force transmissibility ( $\mathrm{Ftr}=0.1293$ ).

2. ANOVA shows Spring Stiffness (K2) is most affecting parameter on Ftr.

\section{REFERENCES}

[1] Adigunaa, H, M Tiwaria, and H E Tsengb. "Transient Response of a Hydraulic Engine Mount." Scientific Research Laboratory, Center of Automotive Research Oh43210-1107, No. Mi48124 (Dec 2002).

[2] Gaul, L N. "Substructure Behavior of Resilient Support Mounts for Single and Double Stage Mounting Systems." Mechanical Systems and Signal Processing. 5(1991).

[3] Hutton, S G. Optimization of Vibration Mounts Properties for Application to Shipboard Diesel Engines. Technical Report Drea Cr 2000-077, Defence Research Establishment Atlantic, Jan 2001.

[4] Joong, Jae Kim, and Young Kim Heon. "Shape Design of an Engine Mount by a Method of Parameter Optimization." Kwangmyungshi,Kyungki (Deparment of mehanical engineering, Kwangweon national univercity), may 1994: 781-88.

[5] Muravyov, A, and S G Hutton. "Analysis of an Engine-Mount System with Time-Dependent and Velocity Matrices." Univercity of British Columbia, Vancouver. Canada: Department of Mechanical, 14 August 1997.Peter, J, Ran Tian, 
G.C.Mekalke, R.R.Kolhapure," Analytical and Parametric Optimization of Force Transmissibility by Taguchi Method for Double Stage Engine Mountings", International Journal of Computer Engineering In Research Trends, Volume 3, Issue 9, September-2016, pp. 461-471

and K Chris. "A Study of Vibration and Vibration Control of Ship Structures." Marine Structures 22(4) (2009): 730-743.

[6] Ramachandran, T, And K P Padmanaban. "Review On Internal Combustion Engine Vibrations and Mountings." Psna Collegge of Engineering and Technology, Dindigul. Tamilnadu.

[7] Singh, R. "Dynamic Design of Automotive Systems: Engine Mounts and Structural Loints." Department of Mechanical Engineering, Ohio State Univercity.

[8] Tao, J S, and G R Liu. "Design optimization of marine engine mount system." journal of sound and vibration 235(3) (2000): 474-494.

[9] Vijayan, V, And T Karthikeyan. "Design and Analysis of Compliant Mechanism for Active Vibration Isolation Using Fea Technique." International Journal of Recent Trends in Engineering 1, No.5 (May 2009).

[10] Yunhe, Yu, G Naganathan Nagi, and v Dukkipati Rao. "A literature review of automotive vehicle engine mounting systems." Mechanical, Industrial and Manufacturing Journal (The univercity of Toledo) Ct06430, no. OH43606 (1999).

[11]Durairaj M., Sudharsun D., Swamynathan N., (2013) "Analysis of Process Parameters in Wire EDM with Stainless Steel using Single Objective Taguchi Method and Multi Objective Grey Relational Grade," Procedia Engineering, 64 ,868- 877 .

[12] Raghuraman S., Thiruppathi K., Panneerselvam T., Santosh S., (2013) "Optimization of EDM Parameters using Taguchi Method and Grey Relation Analysis for Mild Steel IS 2026," International Journal of Innovative Research in Science, Engineering and Technilogy,2,7,3095-3104.
[13]Dean E., (1991) “Taguchi Approach to Design Optimization for Quality and Cost: An Overview," Annual Conference of the International Society of Parametric Analysis, 19.

[14] Rao R., (2011), "Advanced Modeling and optimization of Manufacturing Processes," International Research and Development Springer, 1-380. 